\title{
Cellular and humoral immunodeficiency in breast cancer patients resistant to hormone therapy
}

\author{
E. ZAVADOVA ${ }^{1, *}$, M. VOCKA ${ }^{1}$, J. SPACEK ${ }^{1}$, B. KONOPASEK ${ }^{1}$, T. FUCIKOVA ${ }^{2}$, L. PETRUZELKA ${ }^{1, *}$
}

${ }^{1}$ Charles University in Prague, First Faculty of Medicine, Department of Oncology of the First Faculty of Medicine and General Teaching Hospital, U Nemocnice 2, Prague 2, 12808 Czech Republic; ${ }^{2}$ Charles University in Prague, First Faculty of Medicine, Institute of Immunology and Microbiology of the First Faculty of Medicine and General University Hospital, Studničkova 7, Prague 2, 12808 Czech Republic

${ }^{*}$ Correspondence: ezavadova@seznam.cz

Received January 25, 2013 / Accepted May 29, 2013

In view of the fact that insufficiency in immune response often correlates with poor prognosis, research in recent years has focused on the task of describing the precise status and function of the immune system and its possible effect on cancer patients. Although more than two thirds of treated patients respond to endocrine therapy, most patients with metastatic breast cancer develop a resistance to it. Estrogen modulates angiogenesis, partially through its effects on vascular endothelial growth factor (VEGF). It also appears that transforming growth factor-beta (TGF beta) could be another factor contributing to this resistance. TGF beta is a highly immunosuppressive factor that inhibits natural and specific immunity against tumors and stimulates the production of VEGF.

The purpose of the study was to monitor immune responses in patients with hormone receptor-positive breast cancer who were resistant to hormone therapy. The examination of cellular components (CD4, CD8, HLA-DR, NK cells) and humoral immunity (IgG, IgG subclasses, IgA, IgM,). TGF beta and VEGF production were monitored with special attention, along with an analysis of the changes that occurred during the hormonal treatment. 68 patients included in the research project were implemented with routine cancer treatment with endocrine therapy. Basic parameters (the histological type and grade, the degree of expression of estrogen receptors (ER) and progesterone receptors (PR), human epidermal growth factor receptor 2 (HER2), and the proliferative marker) were established. Patients were evaluated by a cancer clinical immunologist to exclude immune disorders, allergic or autoimmune origin. TGF beta and VEGF were measured by ELISA and antitumor cellular immunity (CD4, CD8) was measured by flow cytometry. Patients who failed in the first line of hormone therapy treatment were considered as resistant to hormone therapy.

Depression in cellular immunity was found especially in patients with resistance to endocrine therapy. In addition, immunoglobulin plasma levels were decreased (mainly IgG4 subtype). Most patients showed clinical symptoms of immunodeficiency (frequent infections of respiratory or urinary tract, herpetic infections). Significant increases in TGF beta and VEGF plasma were also detected.

The correlation of these factors with resistance to hormonal therapy and the state of anticancer immunity could be helpful in the task of predicting resistance to hormonal therapy and could contribute to the selection of targeted immune therapy in cancer patients in the future.

Key words: breast cancer, immunodeficiency, TGF beta, VEGF

Despite recent diagnostic and therapeutic advances, breast cancer remains the second leading cause of cancer mortality in females in affluent countries. The etiology of breast cancer is complicated and not completely understood. Recent studies have focused on the roles of immunity and inflammation $[1,2]$.

The immune response may play an important role in cancer progression. An active antitumor immune profile usually correlates with improved chances of survival. In breast cancer, some studies have reported that cytotoxic lymphocyte infiltration is associated with better survival. It has been shown that $\mathrm{CD}^{+}$lymphocyte infiltration is an independent favorable prognostic indicator in basal-like breast cancer $[3,4,5]$.

CD8+ T cell-mediated type 1 immune responses can enhance the accumulation of distinct endogenous CD8+ and 
CD4+ T cells and facilitate their antitumor function within the tumor microenvironment $[6,7]$. Correspondingly, $\mathrm{T}$ cell deficiency or disruption of specific cytotoxic mechanisms can render experimental animals more susceptible to spontaneous or chemical carcinogenesis $[8,9]$. In metastatic breast cancer patients, the number of treatment cycles influences the development of cytotoxic T cells [10].

Another factor contributing to immunodeficiency might be transforming growth factor-beta (TGF beta), a neoangiogenetic and potent immunosuppressive factor reducing cellular anti-tumor immunity (inhibition of antigen-presenting cells, NK cells, stimulation of T regulatory cells).

Breast cancers are comprised of heterogeneous subtypes of various prognoses. Hormonal therapy is the basic treatment for patients with hormonal dependent breast cancer. Increased expression of hormonal receptors is an important condition of the effectiveness of hormonal therapy. Despite a rise in the use of selective aromatase inhibitors, antiestrogen therapy is still very important. Estrogen's modes of actions are transmitted into the cell through nuclear receptors (estrogen receptors (ER)/progesterone receptors (PR)). After activation, those receptors serve (together with other regulatory molecules) as transcription regulators. Increased expression of hormonal receptors is an important condition in the effectiveness of hormonal therapy. Antiestrogens are the base of hormonal treatment in patients with hormone-dependent breast cancer, and those patients with metastatic disease receive hormonal therapy in the neoadjuvant as well as in the adjuvant indication. Although more than $2 / 3$ of treated patients respond to hormonal therapy, the effectiveness of hormonal treatment is mostly time-limited as most patients develop a resistance to this treatment. Developing resistance in patients with hormonal dependent carcinomas is a complex process, which interferes with intracellular signal transduction on the molecular level.

Endocrine therapy is widely used for estrogen-receptor-positive breast cancer. However, many of these patients experience a recurrence in spite of endocrine therapy, by incompletely understood mechanisms. The variability in distant recurrence-free survival found in endocrine-treated patients may be a result of differences in drug metabolism. There are some publications showing that resistance to endocrine therapy could be due to differences in activity in metabolic enzymes as a result of genetic polymorphism [11]. However, results are in contradiction to prior hypotheses and the present sample size is relatively small.

Apart from human epidermal growth factor receptor 2 (HER2), there are no known predictive markers of resistance to antiestrogen therapy. The role of TGF beta, influencing hormonal receptors and being a potent immunosuppressive factor reducing cellular antitumor immunity, is currently being discussed [10]. Molecular prediction of resistance could provide an opportunity to optimize therapy strategy. Developing resistance in patients with hormonal dependent carcinomas is a complex process, which interferes with intracellular signal transduction on the molecular level. It was shown, that aside from activated HER pathway, TGF beta plays an important role in hormonal resistance and that TGF beta may influence hormonal receptors $[12,13]$.

Paradoxical acting of TGF beta could be based on disruption of the balance between various signaling pathways, such as Smad and Ras/MAPK pathways, which are involved in mediating, and tumor suppressor and anti oncogenetic effect of TGF beta. Smad and Ras/MAPK pathways also seem to have a central role in the HER signaling pathway [14].

Estrogens stimulate positive elements of growth factor signaling pathways, including cell attachment factors which may facilitate growth factor-directed cell proliferation. Estrogens can promote the autocrine expression of growth factor signaling pathway components and inhibit growth factor signaling pathways. It was shown that there is an estrogen and growth factor cross-talk and endocrine insensitivity and acquired resistance in breast cancer [15].

Although TGF beta is known as a marker of invasiveness and metastatic capacity in breast cancer cells, this marker has never been considered to be introduced in routine clinical setting. TGF beta is an ER regulated biomarker which acts synergistically with HER2.

Clinical significance of determination ER and HER2 status could be improved, when they are related with TGF beta as additional biomarker. It seems that TGF beta could make a difference regarding prognosis and prediction in breast cancer patients.

It was shown that TGF is involved in tumor malignancy and lymph node metastasis and could be used clinically as a useful tumor marker for evaluating the extension and the outcome of the disease. There is also some clinical evidence for a significant association between HER2 and serum TGF , resulting in more aggressive phenotype of the tumor and poor prognosis [16].

Proliferation of many breast cancer cells is under the control of sex steroids estrogen and progesterone. Such proliferation allows for an expansion of tumor tissue which requires new blood vessels for nourishment.

Estrogens influence angiogenetic processes resulting into metastasis particularly through vascular endothelial growth factor (VEGF), natural and synthetic progestins induce VEGF in breast cancer cells through the progesterone receptor [17]. VEGF is a key mediator of angiogenesis. VEGF-targeting therapies have shown significant benefits and have been successfully integrated in the routine clinical practice for other types of cancer, such as metastatic colorectal cancer.

An increasing amount of data is evolving in preclinical models, suggesting that ovarian steroids cause cyclical changes, which have an impact on angiogenesis, and estrogen modulates angiogenesis, in part, through the effects on VEGF.

Progesterone mechanisms involved in progesterone effects on genes implicated in control of cell cycle, proliferation, 
angiogenesis and metastasis, such as epidermal growth factor receptor (EGFR), whose promoters lack sequences, and VEGF which gene contains progesterone response elements in its promoter region [18].

Therefore VEGF as well as TGF beta are suggested to act as predictive markers of the disease progression. VEGF is a multifunctional glycoprotein acting as a specific mitogen for endothelial cells and increasing vascular permeability as well. High VEGF levels were described in various human cancer types (breast cancer, endometrial cancer, and ovarian cancer) and the correlation of VEGF levels with the therapy response, disease stage and bad prognosis are currently being discussed. VEGF is a neo-angiogentetic factor increasing tumor neovascularization and metastasizing [19].

The aim of the study was to seek new predictive markers of therapy response in breast cancer patients who were resistant to hormone therapy in particular immunity response by monitoring TGF beta and VEGF plasma levels as well as the cellular immunity response (CD8, CD4).

\section{Materials and methods}

Study subjects. Between 2010 and 2012, 68 patients with breast cancer who were resistant to hormone therapy were involved in the study. Patients who failed in the first line of hormone therapy treatment were considered as resistant to hormone therapy.

The histological type and grade, the degree of expression of ER and PR, HER2, and the proliferative marker were established. Patients were treated according to standard therapy protocols and indications, in standard doses. The 68 examined adult women with histologically confirmed invasive breast cancer had a median age of 56 years. Of these women 55 were postmenopausal (81\%) and 13 premenopausal (19\%). 63 women underwent surgery. Ablation with exenteration of axilla was done in 25 cases, partial resection with exenteration of axilla in 25 cases and with sentinel lymph node dissection in 13 cases. 5 women not underwent surgery due to a locally advanced disease or generalization. 1 patient was staged as 0 at the time of operation (after neoadjuvant treatment), 35 patients were staged as I, 25 as II, 5 as III and 2 as IV. From the histological point of view it was mainly invasive ductal carcinoma, namely in 52 cases. Lobular cancer was diagnosed in 11 cases and other histological type in 5 cases. All tumors were hormonal dependent, ER and PR were present in all of them. In 50 cases ER were positive for more than $50 \%$ of the cells. In 16 cases, between 5 and $50 \%$ and in 2 cases under $5 \%$. In 35 cases PR were positive for more than $50 \%$ of the cells. In 27 cases, between 5 and $50 \%$ and in 6 cases under 5\%. In all cases HER2 was negative. Patients in this study have had similar treatment cycles. All patients were treated by neoadjuvant or adjuvant chemotherapy (AC-D $[4 \mathrm{x}$ doxorubicin with cyclophosphamide and then 4 times docetaxel], FEC [ 6 cycles of fluorouracil, epirubicin and cyclophosphamide] or CMF [6 cycles cyclophosphamide, methotrexate and fluorouracil]) and all patients were at least 2 years without chemotherapy in the time of sample collection. In the first line of hormonal therapy 53 women were treated with tamoxifen, 14 with aromatase inhibitor and 1 with exemestane. In the second line chemotherapy tamoxifen was given to one patient, aromatase inhibitor to 22 women, exemestane to 3 and fulvestrant to 3 women. After progression, a third line of hormonal therapy was given to 16 women (to 2 aromatase inhibitor and to 14 fulvestrant) and a fourth line was given to 3 women (to 2 exemestane and to 1 fulvestrant). Patients were evaluated by a clinical immunologist to exclude immune disorders, such as allergy, autoimmunity or immunodeficiency.

The control group comprises of 48 healthy women with normal laboratory results in cellular as well as in humoral immunity, with a median age of 53 years. 39 of the women were postmenopausal and 9 premenopausal.

TGF beta and VEGF determination assay. For each sample, $5 \mathrm{ml}$ of plasma was collected into a polypropylene tube and stored at $-20^{\circ} \mathrm{C}$. Plasma TGF beta level was determined by capture ELISA according to the instructions given by the manufacturer (R\&D Systems, Inc. USA), using Monoclonal Anti-human TGF beta Antibody, (R\&D Systems, Inc. USA). Plasma VEGF level was determined by capture ELISA Systems using Monoclonal Anti-human VEFG Antibody R\&D Systems. In brief, $100 \mu$ l of the capture antibody was transferred to an ELISA plate and incubated overnight at room temperature. Each well was then washed three times with a wash buffer. After removing the buffer, the plates were blocked by adding $300 \mu \mathrm{l}$ of phosphate-buffered saline (PBS) containing $0.05 \%$ Tween, $5 \%$ sucrose and $0.05 \%$ $\mathrm{NaN} 3$ to each well and incubating at room temperature for a minimum of 1 hour. $100 \mu \mathrm{l}$ of blood plasma sample per well was added, the ELISA plate was covered with an adhesive strip and incubated for 2 hours at room temperature. $100 \mu \mathrm{l}$ of streptavidin HRP (R\&D Systems, 1/200 in appropriate diluent) was added to each well; the plate was covered and incubated for 20 minutes at room temperature. After subsequent addition of Substrate Solution and Stop Solution (both R\&D Systems, Inc.), the optical density of each well was determined within 30 minutes, using a microplate reader set to $450 \mathrm{~nm}$.

Flow cytometry. Antitumor cellular immunity (CD4, CD8, NK cells, HLA-DR) was measured by flow cytometry. (Cytometr Navios, Software Navios, v.01 Beckman Coulter, monoclonal antibodies: CD4-APC-Alexa Fluor 750, clone 13B8.2, IgG1, cat. no A94682 Beckman Coulter, CD8-Phycoerythrin-Cyanine7, clone SFCI21Thy2D3, IgG1, cat. no 737661 Beckman Coulter, CD16-Phycoerythrin, clone 3G8, IgG1, cat. no A07766 Beckman Coulter, CD3/HLA-DR-Fluorescein isothiocyanate/Phycoerythrin, clone UCHT1, IgG1/IgG1, cat. no A07737 Beckman Coulter, Isotypic Control-Fluorescein isothiocyanate/Phycoerythrin, clone 679.1Mc7, IgG1/IgG1, cat. no A07794 Beckman Coulter, CD45/CD56/CD19/CD3-Fluorescein isothiocyanate/Phycoerythrin/Phycoerythrin-Texas 


\section{TGF beta}

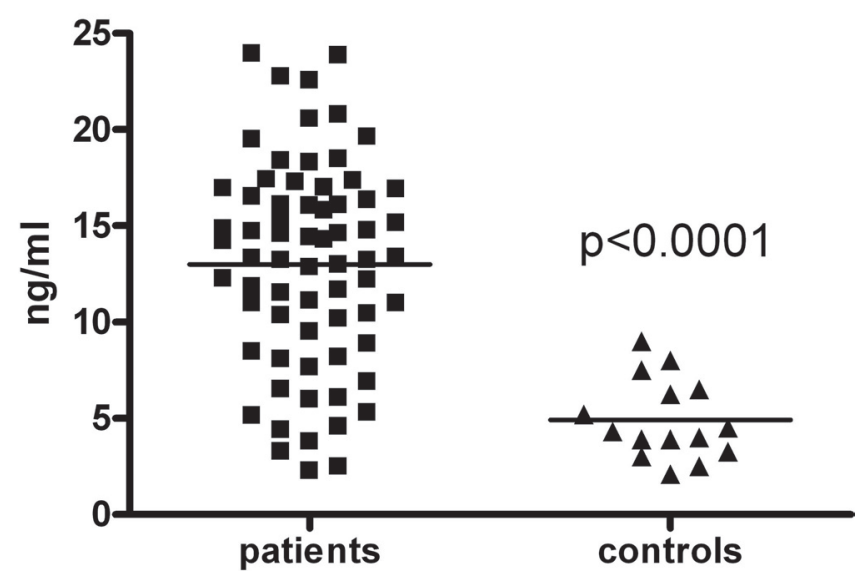

Figure 1. TGF beta in plasma of breast cancer patients as compared with control, the plasma levels of TGF beta were significantly increased $[\mathrm{p}<0.0001]$.

Red-X/Phycoerythrin-Cyanine5, clone B3821F4A/N901NKH1/J3-119/UCHT1, IgG2b/IgG1/IgG1/IgG1, cat. no 6607073 Beckman Coulter).

Determination of Immunoglobulins was done by Beckman Coulter Immage 800 Immunochemistry System (Nelphelometry).

Statistics. For statistical analysis, Prism 4 (Graph Pad Software Inc.) was used. The relationships between variables were obtained using Spearman's nonparametric test and differences between variables were determined by employing the Mann-Whitney U-test. A statistical comparison of intra- and inter-individual variation was carried out by use of one-way analysis of variance (ANOVA).

\section{Results}

TGF beta. In the group of 68 patients with hormone resistant breast cancer, the plasma levels of TGF beta were significantly increased [ $p<0.001]$, as compared with the healthy controls. The TGF beta results are demonstrated in Fig.1. In patients, TGF beta levels were $13.02 \mathrm{ng} / \mathrm{ml} \pm 5.358$ (mean, standard deviation) as compared with control group $4.927 \mathrm{ng} / \mathrm{ml} \pm 2.084$. There was a significant difference between medians of both groups [p $<0.001]$. In patients, TGF beta levels were $13.34 \mathrm{ng} / \mathrm{ml} \pm 0.6497$ (median, standard error) as compared with control $4.3 \mathrm{ng} / \mathrm{ml} \pm 0.5381$. Maximum of TGF beta level measured in patients' plasma was $23.95 \mathrm{ng} / \mathrm{ml}$, in the healthy control $9 \mathrm{ng} / \mathrm{ml}$.

VEGF. VEGF plasma level was significantly increased $[\mathrm{p}<0.0001]$ in breast cancer patients resistant to hormone therapy (Fig.2). VEGF levels were $95.35 \mathrm{pg} / \mathrm{ml} \pm 66.41$ (mean, standard deviation) as compared with control group $25.8 \mathrm{pg} /$ $\mathrm{ml} \pm 13.39$. There was a significant difference between medians of both groups [ $p<0.001]$. In patients, VEGF levels were 80.6

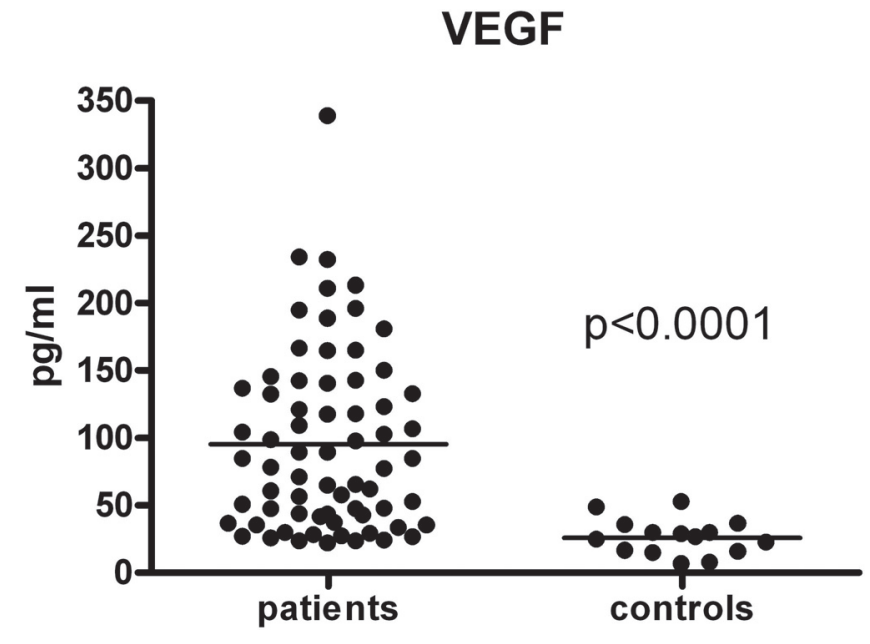

Figure 2. VEGF plasma level in patients with breast cancer as compared with controls, the VEGF plasma level was significantly increased [ $p<$ 0.0001 ].

$\mathrm{pg} / \mathrm{ml} \pm 8.053$ (median, standard error) as compared with control 26.pg/ml \pm 3.456 . Maximum of VEGF level measured in patients' plasma was $338.3 \mathrm{pg} / \mathrm{ml}$, in the healthy control 52 $\mathrm{pg} / \mathrm{ml}$.

Cellular immunity. We observed a significant decrease $[\mathrm{p}<0.0001]$ in cell mediated antitumor immunity, mainly lower level of CD8+ T lymphocytes (cytotoxic effector cells) (Fig.3).

In breast cancer patients resistant to hormone therapy, CD8\% was $24.19 \%, \pm 8.663$ (mean, standard deviation) as compared with the control group $35.67 \% \pm 3.716$. There was a significant difference between medians of both groups $[\mathrm{p}<$ 0.001]. In patients, CD8\% was $24 \pm 1.051$ (median, standard

\section{$\%$ of Cytotoxic Lymfocytes [CD8]}

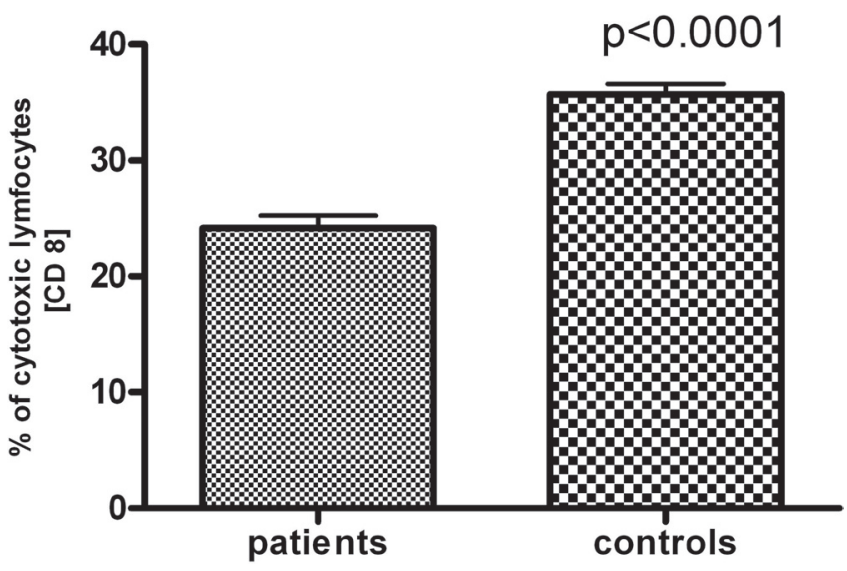

Figure 3. Cytotoxic T lymphocytes (CD8\%) in patients with breast cancer as compared with controls, the level of CD8+ T lymphocytes (cytotoxic effector cells) was significantly lowered. 


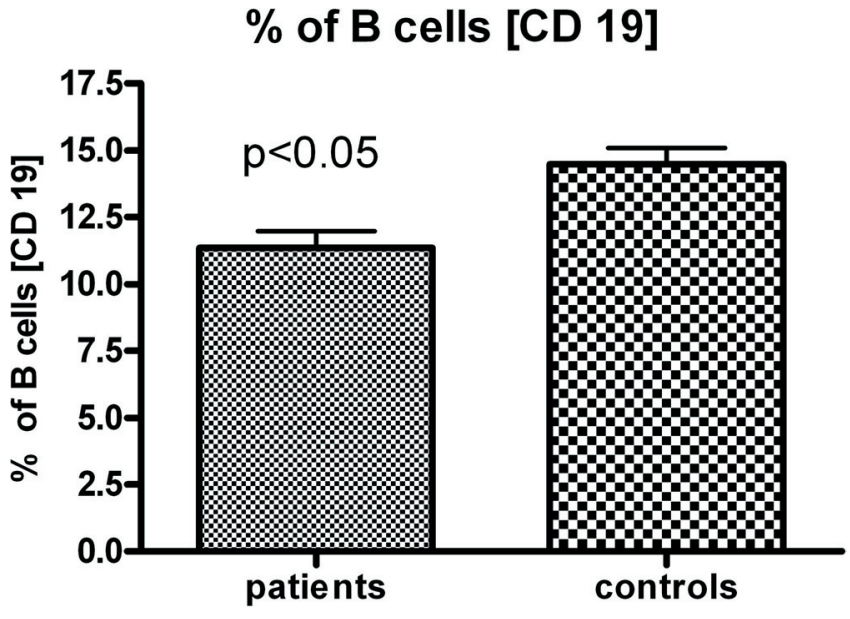

Figure 4. B cells (CD19) in patients with breast cancer as compared with controls. The percentage and absolute number of B lymphocytes (CD19) was decreased $[\mathrm{p}<0.05]$.

error) as compared with the control $36 \% \pm 0.9595$. Minimum of CD8\% in patients was $12 \%$, in the healthy control $30 \%$. Maximum of CD $8 \%$ in patients' plasma was $46 \%$, in the healthy control $42 \%$.

The percentage of B lymphocytes (CD19) was also decreased [ $<<0.05]$. Results are demonstrated in Fig.4. In breast cancer patients resistant to hormone therapy, B cells \% was $11.35 \%, \pm 5.09$ (mean, standard deviation) as compared with control group $14.47 \%, \pm 2.386$. There was a significant difference between medians of both groups $[\mathrm{p}<0.05]$. In patients, $\mathrm{B}$ cells \% was $12 \pm 0.6172$ (median, standard error) as compared with control $14 \pm 0.6162$. Minimum of B cells \% in patients' plasma was $2 \%$, in the healthy control $11 \%$. Maximum of CD8\% in patients plasma was $11 \%$, in the healthy control 20 $\%$. The level of antigen presenting cells (HLA-DR positive) was not alternate.

Humoral immunity. In humoral immunity, there was a significant decrease $[\mathrm{p}<0.0001]$ of immunoglobulins levels mainly in class IgG4. Results are demonstrated in Fig.5.

IgG4 levels in breast cancer patients were $0.7248 \mathrm{U} / \mathrm{ml} \pm$ 1.364 (mean, standard deviation) as compared with the healthy control group $1.149 \mathrm{U} / \mathrm{ml} \pm 0.2473$. There was a significant difference between medians of both groups [ $\mathrm{p}<0.001]$. In patients, IgG4 levels were $0.45 \mathrm{U} / \mathrm{ml} \pm 0.1654$ (median, standard error) as compared with the control group $1.20 \mathrm{U} / \mathrm{ml} \pm 0.0639$. Maximum of IgG4 level measured in the patients' plasma was $11 \mathrm{U} / \mathrm{ml}$, in the healthy control $1.4 \mathrm{U} / \mathrm{ml}$. Minimum of IgG4 level measured in the patients plasma was $0.019 / \mathrm{ml}$, in the healthy control $0.66 \mathrm{U} / \mathrm{ml}$.

There were symptoms of immunodeficiency such as repeated infections of upper respiratory tract, infections of urinary tract and herpetic infections, in $90 \%$ of patients. In $50 \%$ of cases, there were recognized serological signs of active and chronic chlamydial infections. Zoster virus was found in

\section{Immunoglobulin (IgG4)}

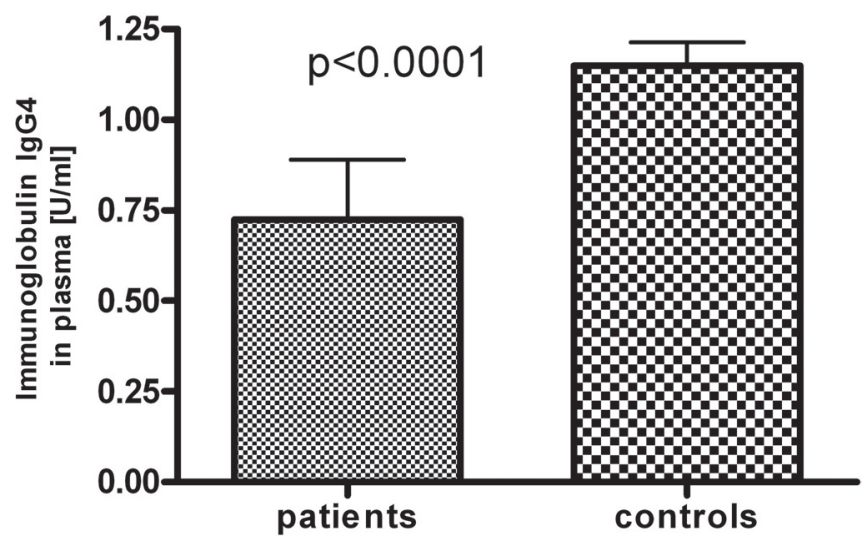

Figure 5. Immunoglobulins levels (IgG4) in humoral immunity in patients with breast cancer as compared with controls, there was a significant decrease [p $<0.0001]$ of immunoglobulins levels mainly in class IgG4.

4.3\% and anamnestic antibodies against Borrelia were elevated in $34.50 \%$.

\section{Discussion}

Immune-regulated pathways influence multiple aspects of cancer development. It has been shown that T-cell abundance in breast cancer represents prognostic indicators for recurrence-free and overall survival [20]. Evidence exists to show that response to chemotherapy is partly regulated by these lymphocytes. Experimental studies have recently revealed that $\mathrm{B}$ and $\mathrm{T}$ lymphocytes can exert pro-tumor activity indirectly by regulating the bioactivity of myeloid cells, including macrophages, monocytes, and mast cells, resulting in resistance to endocrine therapies and the development of metastasis $[21,22,23]$.

Moreover, it was shown that stimulating T cell responseadministering the anti-CTLA4 monoclonal antibody (mAb) tremelimumab to patients with breast cancer advanced hormone responsive breast cancer was associated in most patients with increased peripheral CD4+ and CD8+ T cells [24].

Breast cancer is a heterogeneous disease composed of different intrinsic subtypes, each with distinctive biological and prognostic behavior and responses to therapy. Although the introduction of adjuvant systemic therapy (AST) has led to a significant reduction in breast cancer mortality, many patients do not benefit. Studies of gene expression suggest that predictive indicators should be developed for different breast cancer subtypes $[25,26]$. The interaction between immune response, cancer subtype, and treatment strategy are all likely to contribute to the outcome of the disease.

Therefore, there is a clear need for studies with sufficient power for subgroup analysis, employing validated measure- 
ments of immune response, to evaluate the significance of immune response in breast tumors.

The aim of this study was to examine the prognostic significance of immune response $\left(\mathrm{CD}^{+}\right)$in breast cancer patients resistant to hormone therapy. Our hypothesis was that $\mathrm{CD} 8^{+}$ lymphocyte population and immune response is decreased in endocrine therapy resistant breast cancer.

In patients with resistance to hormone therapy we found mainly defects of cellular antitumor immunity - lower expression of CD8 (the cytotoxic T lymphocytes). Levels of both TGF beta and VEGF were increased. Decreased humoral component of immunity, including the clinical manifestations of immunodeficiency, was found in many of these patients.

Accumulating evidence indicates that malignant cells exert a major control on their non-malignant neighbours. Thus, most cancer cells not only promote angiogenesis to support tumor growth beyond the size limit that would be dictated by a poorly vascularized microenvironment $[27,28]$, but also activate metabolic circuitries whereby stromal cells are de facto revived to function as a feeder compartment, generating large amounts of energetic products such as lactate and ketone bodies $[29,30]$. Cancer-associated fibroblasts (CAFs) are prominent sources of mitogenic and pro-angiogenic factors such as interleukin (IL)- 6 and VEGF [31]. Furthermore, cancer cells, either directly or through CAFs, produce a wide array of cytokines including TGF beta and IL-10 that exert potent immunosuppressive effects [32]. Altogether, these observations demonstrate that during oncogenesis, malignant cells become capable of co-opting the local microenvironment in order to satisfy their own metabolic and immunological needs. TGF beta ligands are often enriched in the tumor microenvironment and can be produced by tumor cells or by tumor-associated stromal and immune cells $[33,34]$. These data suggest the possibility that the TGF beta pathway is involved in maintenance of breast carcinomas [35].

Current endocrine therapies are not effective in all patients (de novo endocrine resistance), while initially responsive tumors will sooner or later progress despite such treatments (acquired resistance), inevitably resulting in patient relapse and, ultimately, death. Identification of the factors and pathways responsible for the development of these resistant conditions is therefore an important diagnostic and therapeutic goal in cancer research.

TGF beta plays an important role in the hormonal resistance and may influence hormonal receptors $[12,13]$.

There is increasing evidence that there also exists a crosscommunication between ERs and growth factor receptor signaling, such as insulin-like growth factor-1, epidermal growth factor (EGF), TGF alpha, and TGF beta $[36,37]$. Thus, it has been postulated that estrogens negatively modulate TGF beta signaling in breast cancer cells $[38,39]$. TGF beta is also a potent inductor of tumor cell migration contributing to an enhanced metastatic capacity [40]. In particular, in late-stage tumors, the balance between positive and negative effects of
TGF beta on tumor progression may be shifted in favour of its promoting properties, because the sensibility of cells toward the antiproliferative and proapoptotic effects of the chemokine declines because of dysfunctional TGF beta receptors or TGF beta signaling [41].

TGF beta mediates its biological effects mainly via two types of serine/threonine kinase receptors, TGF beta receptor I and TGF beta receptor II, followed by an activation of the Smad signaling pathway. After ligand binding and dimerization of TGF beta receptor I and TGF beta receptor II, receptorregulated Smad2 and Smad3 proteins are phosphorylated and interact with the common mediator Smad4 [42]. These activated Smad complexes translocate into the nucleus to regulate the transcriptional activity of Smad-responsive genes. It has been reported that there exists a cross-communication between estrogens and Smad activation resulting in a reduction of TGF beta functions; however, the underlying cellular processes have not been completely elucidated [38, 39, 43]. It was demonstrated that estrogens inhibit Smad signaling by activation of the extracellular-regulated kinase (ERK1/2). It is interesting that this estrogen-mediated action is transduced via the orphan receptor GPR30 [44].

Some authors propose that the presence of an activated TGF beta pathway is associated with intrinsic resistance to hormone therapy. They identified 25 regulated genes that might be strong predictors of ER+ tumor response to neoadjuvant therapy. Among these were 4 genes associated with TGF beta signaling.

TGF beta is a multifunctional growth factor and there is increasing evidence that its enhanced expression promotes breast cancer progression contributing to tumor invasiveness and metastasis. Indeed, it has been suggested that in addition to ER, TGF beta could serve as a biomarker of poor prognosis or hormone resistance in breast cancer patients [45].

An increasing amount of data is evolving in preclinical models, suggesting that ovarian steroids cause cyclical changes, which have an impact on angiogenesis, and estrogen modulates angiogenesis, in part, through the effects on VEGF.

VEGF is a key molecule in promoting blood vessel growth. VEGF-targeting therapies are a new class of drugs designed to target a specific molecule. One of these drugs is bevacizumab (Avastin) which has been studied in clinical trials in metastatic breast cancer.

Wagner at all showed that the addition of bevacizumab to chemotherapy in patients, which have had progressed on hormonal treatment, significantly prolongs progression-free survival and response rates in patients who have had previous chemotherapy and those who have not had previous chemotherapy for metastatic disease [46]. By contrast, individual trial results in metastatic breast cancer are highly variable and their value is controversial.

Breast cancer is a very heterogeneous disease considering a number of biomarkers which are under investigation. However, most important biomarkers in a clinical setting are ER and HER2. 
VEGF as well as TGF beta was reported as a prognostic marker in breast cancer patients.

TGF beta inhibitors have been proposed and are being developed as anti-metastatic therapies in patients with cancer, anti VEGF therapy is currently used in breast cancer patients.

In our study we focused on the subgroup of breast cancer patients with resistance to hormone therapy, since there are no published data regarding this group of patients. We did not see any relationship between TGF beta and VEGF levels and surgery types, but it had been previously published, that patients with positive sentinel lymph node have higher preoperative levels of TGF beta and VEGF than patients with negative sentinel lymph node [47]. Since it was shown that the number of treatment cycles affects immune response in breast cancer patients, patients in this study had similar treatment cycles. All patients were treated by neoadjuvant or adjuvant chemotherapy (AC-D [ $4 \mathrm{x}$ doxorubicin with cyclophosphamide and then 4 times docetaxel], FEC [6 cycles of fluorouracil, epirubicin and cyclophosphamide] or CMF [6 cycles cyclophosphamide, methotrexate and fluorouracil]) and all patients were at least 2 years without chemotherapy in time of sample collection. We did not see any correlation between the expression levels of TGF beta and VEGF and the stages of cancers, but this could be due to small patients number in stage I, stage III, and IV. More research regarding this subgroup of patients should be done in the future.

The aim of our study was to find out whether TGF beta and VEGF plasma levels as well as the cellular immunity correlate with the hormonal resistance development. Our results suggest that the overproduction of neoangiogenetic and immunosuppressive factors is enhanced in patients resistant to endocrine therapy. The correlation of these factors with resistance to hormonal therapy and immune status could refine the prediction of resistance and contribute to any targeted immune intervention therapy and targeted selection of cancer treatment. In the future this finding could help to seek new risk predictive markers in breast cancer patients. These patients may benefit from immunomodulatory treatment (substitution of immunoglobulins, immune cell stimulation, etc.).

More studies are necessary in order to show whether those factors can be used for adjusting individual therapy in patients with hormonally dependent breast cancer. A detailed immunologic exam, specially focused on TGF beta and VEGF level determination, could identify the risk group of patients with early or late resistance to hormonal therapy. Patients with elevated TGF beta or VEGF levels can receive intensive dispensary care, or chemoprevention could possibly be recommended. In the case of confirmed TGF beta or VEGF elevation and alteration of cellular immunity in a wider study, another prognostic-predictive marker influencing therapy protocol could be obtained. TGF beta and VEGF determination could serve as an additional marker monitoring clinical status during endocrine therapy. In the future it would also be important to evaluate disease-free time and overall survival time. In the case of correlation of high TGF beta or VEGF plasma level with overall survival time additive immunotherapy could be recommended (suppression of VEGF or TGF beta overproduction with monoclonal antibodies, stimulation of antigen presentation, NK cells an CD8 cells support). Clear statement about the role of VEGF and TGF beta and possible correlation with resistance to hormonal therapy and impaired status of cellular immunity (mostly inhibition of CD8 effector lymphocytes killing the tumor cells) could not only support the prediction of resistance and help to choose appropriate therapy, but could also help to decide other important questions: whether or not to choose more aggressive therapy. Such correlation can even show new possibilities regarding immunotherapy (stimulation of antitumor immunity, stimulation of antigen presenting cells and downregulation of TGF beta and VEGF overproduction combined with hormonal therapy.)

Besides the significant decrease of CD8 T lymphocytes we observed also decrease of total CD 3 (n.s). T lymphocytes with cytotoxic function (CD8) are forced and exhausted because of recurrent infections, probably also due to IgG4 immunodeficiency.

In cancer patients, immunity defense is decreased not only because of cancer disease, but also owing to repeated infections connected with IgG4 immunodeficiency. This immunodeficiency is supported with the production of immunosuppressive factors (TGF beta and VEGF).

It could be assumed that defective anti-infective as well as anticancer immune response could be compensated by higher activity of NK cells-in our patients we found either higher NK percentage in peripheral blood or other activation of immune system (HLA-DR expression was not enhanced). This immune suppression is probably due to an overproduction of suppressive mediators such as TGF beta or VEGF. Immunosuppression and insufficient anticancer immune defense might also be due to exhausted immune system caused by repeated bacterial and viral infections.

Based on our results and experience, we assume that describing and investigating basic immunity parameters in cancer patients should be a part of oncology care. In the case of proved immunodeficiency, patients may benefit from immunomodulatory therapy according to the guidelines used in clinical immunology in the treatment of immunopathologic disorders.

Acknowledgments: This project was supported by grant IGA NT 11168-3/2010, IGA NT 13259-3/2012 and PRVOUK.

\section{References}

[1] JEHN CF, FLATH B, STRUX A, KREBS M, POSSINGER K et al. Influence of age, performance status, cancer activity, and IL- 6 on anxiety and depression in patients with metastatic breast cancer. Breast Cancer Res Treat 2012; 136: 789-794. http://dx.doi.org/10.1007/s10549-012-2311-2 
[2] GRIVENNIKOV S, GRETEN F, KARIN M Immunity, inflammation, and cancer. Cell 2010; 140: 883-899. http://dx.doi. org/10.1016/j.cell.2010.01.025

[3] LEE AH, GILLETT CE, RYDER K, FETIMAN IS, MILES DW et al. Different patterns of inflammation and prognosis in invasive carcinoma of the breast. Histopathology 2006; 48: 692-701. http://dx.doi.org/10.1111/j.1365-2559.2006.02410. $\underline{\mathrm{X}}$

[4] RUFFEL B, AU A, RUGO HS, ESSERMAN LJ, HWANG ES et al. Leukocyte composition of human breast cancer. Proc Natl Acad Sci USA 2012; 109: 2796-2801. http://dx.doi. org/10.1073/pnas. 1104303108

[5] LIU S, LACHAPELLE J, LEUNG S, GAO D, FOULKES WD CD8+ lymphocyte infiltration is an independent favorable prognostic indicator in basal-like breast cancer. Breast Cancer Res 2012; 14: R48. http://dx.doi.org/10.1186/bcr3148

[6] SCHILLACI R, SALATINO M, CASSATARO J, PROIETTI CJ, GIAMBARTOLOMEI GH Immunization with murine breast cancer cells treated with antisense oligodeoxynucleotides to type I insulin-like growth factor receptor induced an antitumoral effect mediated by a CD8+ response involving Fas/Fas ligand cytotoxic pathway. J Immunol 2006; 176: 3426-3437.

[7] DOBRZANSKI MJ, REOME JB, HYLIND JC, REWERSFELKINS KA CD8-mediated type 1 anti-tumor responses selectively modulate endogenous differentiated and nondifferentiated $\mathrm{T}$ cell localization, activation, and function in progressive breast cancer. J Immunol 2006; 177: 8191-8201.

[8] SHANKARAN V, IKEDA H, BRUCE AT, WHITE JM, SWANSON PE IFNgamma and lymphocytes prevent primary tumor development and shape tumor immunogenicity. Nature 2001; 410: 1107-1111. http://dx.doi.org/10.1038/35074122

[9] SWANN JB, SMYTH MJ Immune surveillance of tumors. J Clin Invest 2007; 117: 1137-1146. [11 Wegman 2005] WEGMAN P, VAINIKKA L, STAL O, NORDENSKJOLD B, SKOOG L, RUTQVIST LE, WINGREN S Genotype of metabolic enzymes and the benefit of Tamoxifen in postmenopausal breast cancer patients. Breast Cancer Res 2005; 7: R284-R290. http://dx.doi.org/10.1186/bcr993

[10] WRIGHT SE, REWERS-FELKINS KA, QUINLIN IS, PHILLIPS CA, TOWNSEND $\mathrm{M}$ et al. Number of treatment cycles influences development of cytotoxic T cells in metastatic breast cancer patients - a phase I/II study. Immunol Invest 2010; 39 : 570-586. http://dx.doi.org/10.3109/08820131003713798

[12] TODOROVIC-RAKOVIC N TGF-beta 1 could be a missing link in the interplay between ER and HER-2 in breast cancer. Med Hypotheses 2005; 65: 546-551. http://dx.doi.org/10.1016/ j.mehy.2005.03.019

[13] WANG SE, SHIN I, WU FY, FRIEDMAN DB, ARTEAGA Cl HER2/Neu (ErbB2) Signaling to Rac1-Pak1 Is Temporally and Spatially Modulated by Transforming Growth Factor \{beta\}. Cancer Res 2006; 66: 9591-9600. http://dx.doi.org/10.1158/ 0008-5472.CAN-06-2071

[14] TODOROVIC-RAKOVIĆ N TGF- $\beta$ and HER2/ErbB2 and breast cancer progression. Transforming growth factor- $\beta$ in cancer therapy. Cancer Drug Discovery and Development 2008; 2: 141-151.
[15] NICHOLSON RI, GEE JMW Oestrogen and growth factor cross-talk and endocrine insensitivity and acquired resistance in breast cancer. British Journal of Cancer 2000; 82: 501-513.

[16] PAPADOPOUlOU E, ANAGNOSTOPOUlOS K, TRIPSIANIS G, TENTES I, KAKOLYRIS S, GALAZIOS G et al. Evaluation of predictive and prognostic significance of serum TGF-betal levels in breast cancer according to HER-2 codon 655 polymorphism. Neoplasma 2008; 55: 229-38.

[17] WU J, RICHER J, HORWITZ KB, HYDER SM Progestindependent induction of vascular endothelial growth factor in human breast cancer cells: preferential regulation by progesterone receptor B. Cancer Res 2004; 64: 2238-2244. http://dx.doi. org/10.1158/0008-5472.CAN-03-3044

[18] HERNANDEZ-HERNANDEZ OT, CAMACHO-ARROYO I Regulation of gene expression by progesterone in cancer cells: effects on cyclin D1, EGFR and VEGF. Mini Review in Medicinal Chemistry 2013; 13: 635-642. http://dx.doi. org/10.2174/1389557511313050002

[19] ZHANG XH, HUANG DP, GUO GL, CHEN GR, WAN L et al. Coexpression of VEGF-C and COX-2 and its association with lymphangiogenesis in human breast cancer. BMC Cancer 2008; 8: 4. http://dx.doi.org/10.1186/1471-2407-8-4

[20] DE NARDO DG, BRENNAN DJ, REXHEPAJ E, RUFFELL B, SHIAO SL Leukocyte complexity predicts breast cancer survival and functionally regulates response to chemotherapy. Cancer Discovery 2011; 1: 54-67. http://dx.doi.org/10.1158/ 2159-8274.CD-10-0028

[21] DE VISSER KE, KORETS LV, COUSSENS LM De novo carcinogenesis promoted by chronic inflammation is $\mathrm{B}$ lymphocyte dependent. Cancer Cell 2005; 7: 411-423. http:// dx.doi.org/10.1016/j.ccr.2005.04.014

[22] AMMIRANTE M, LUO JL, GRIVENNIKOV S, NEDOPASOV S, KARIN M B-cell-derived lymphotoxin promotes castration-resistant prostate cancer. Nature 2010; 464: 302-305. http://dx.doi.org/10.1038/nature08782

[23] DE NARDOL DG, BRENNAN DJ, REXHEPAJ E, RUFFELL B Leukocyte complexity predicts breast cancer survival and functionally regulates response to chemotherapy. Cancer Discovery 2011; 1: 54. http://dx.doi.org/10.1158/2159-8274. CD-10-0028

[24] VONDERHEIDE RH, LO RUSSO PM, KHALIL M, GARTNER EM, KHAIRA Tremelimumab in combination with exemestane in patients with advanced breast cancer and treatment-associated modulation of inducible co-stimulator expression on patient T cells. Clin Cancer Res 2010; 16: 3485-3494. http://dx.doi.org/10.1158/1078-0432.CCR-10$\underline{0505}$

[25] EDEN P, RITZ C, ROSE C, FERNO M, PETERSON C "Good old" clinical markers have similar power in breast cancer prognosis as microarray gene expression profilers. Eur J Cancer 2004; 12: 1837-1841. http://dx.doi.org/10.1016/ j.ejca.2004.02.025

[26] NIME US-MALMSTROM E, RITZ C, EDEN P, JOHNSSON A, OHLSSON M Gene expression profilers and conventional clinical markers to predict distant recurrences for premenopausal breast cancer patients after adjuvant chemotherapy. 
Eur J Cancer 2006; 42: 2729-2737. http://dx.doi.org/10.1016/ j.ejca.2006.06.031

[27] CARMELIET P, JAIN RK Molecular mechanisms and clinical applications of angiogenesis. Nature 2011; 473: 298-307. http://dx.doi.org/10.1038/nature10144

[28] POTENTE M, GERHARDT H, CARMELIET P Basic and therapeutic aspects of angiogenesis. Cell 2011; 146: 873-887. http://dx.doi.org/10.1016/j.cell.2011.08.039

[29] GALLUZZI L, KEPP O, KROEMER G Reverse Warburg: straight to cancer. Cell Cycle 2012; 11: 1059. http://dx.doi. org/10.4161/cc.11.6.19746

[30] WITKIEWIZ AK, WHITAKER-MENEZES D, DASGUPTA A, PHILP NJ, LIN Z, GANDARA R et al. Using the „reverse Warburg effect" to identify high-risk breast cancer patients: stromal MCT4 predicts poor clinical outcome in triplenegative breast cancers. Cell Cycle 2012; 11: 1108-1117. http://dx.doi.org/10.4161/cc.11.6.19530

[31] RASANEN K, VAHERI A Activation of fibroblasts in cancer stroma. Exp Cell Res 2010; 316: 2713-2722. http://dx.doi. org/10.1016/j.yexcr.2010.04.032

[32] RABINOWICH GA, GABRILOVICH D, SOTOMAYOR EM Immunosuppressive strategies that are mediated by tumor cells. Annu Rev Immunol 2007; 25: 267-296. http://dx.doi. org/10.1146/annurev.immunol.25.022106.141609

[33] BIERIE B, MOSES HL Tumour microenvironment: TGF[beta]: the molecular Jekyll and Hyde of cancer. Nat Rev Cancer 2006; 6: 506-520. http://dx.doi.org/10.1038/ $\underline{\text { nrc1926 }}$

[34] BIERIE B, STOVER DG, ABEL TW, CHYTIL A, GORSKA $\mathrm{AE}$ et al. Transforming growth factor- $\beta$ regulates mammary carcinoma cell survival and interaction with the adjacent microenvironment. Cancer Res 2008; 68: 1809-1819. http:// dx.doi.org/10.1158/0008-5472.CAN-07-5597

[35] SENOVILLA L, VACCHELLI E, GALON J, ADJEMIAN S, EGGERMONT A, FRIDMAN WH, SAUTES-FRIDMAN C, MA Y et al. Trial watch, prognostic and predictive value of the immune infiltrate in cancer. Oncoimmunology 2012; 1: 1323-1343. http://dx.doi.org/10.4161/onci.22009

[36] IGNAR-TROWBRIDGE DM, PIMENTEL M, TENG CT, KORACH KS and MCLACHLAN JA Cross talk between peptide growth factor and estrogen receptor signaling systems. Environ Health Perspect 1995; 103: 35-38.

[37] THORNE C and LEE AV Cross talk between estrogen receptor and IGF signaling in normal mammary gland development and breast cancer. Breast Dis 2003; 17: 105-114.
[38] MALEK D, GUST R and KLEUSER B 17-Beta-estradiol inhibits transforming-growth-factor-beta-induced MCF-7 cell migration by Smad3-repression. Eur J Pharmacol 2006; 534: 39-47. http://dx.doi.org/10.1016/j.ejphar.2006.01.025

[39] YOO YA, KIM YH, KIM JS, and SEO JH The functional implications of Akt activity and TGF-beta signaling in tamoxifen-resistant breast cancer. Biochim Biophys Acta 2008; 1783: 438-447.

[40] MURAOKA-COOK RS, DUMONT N and ARTEAGA CL Dual role of transforming growth factor beta in mammary tumorigenesis and metastatic progression. Clin Cancer Res 2005; 11: 937-943.

[41] LEIVO T, LEIVO I, KARINIEMI AL, KESKI-OJA J and VIRTANEN I Down-regulation of transforming growth factor-beta receptors I and II is seen in lesional but not nonlesional psoriatic epidermis. Br J Dermatol 1998; 138: 57-62. http://dx.doi.org/10.1046/j.1365-2133.1998.02026.x

[42] MASSAGUE J TGF-beta signal transduction. Annu Rev Biochem 1998; 67: 753-791. http://dx.doi.org/10.1146/annurev. biochem.67.1.753

[43] CHERLET T and MURPHY LC Estrogen receptors inhibit Smad3 transcriptional activity through Ap-1 transcription factors. Mol Cell Biochem 2007; 306: 33-42. http://dx.doi. org/10.1007/s11010-007-9551-1

[44] KLEUSER B, MALEK D, GUST R, PERTZ HH, POTTECK $\mathrm{H}$ 17-beta-Estradiol inhibits transforming growth factor-beta signaling and function in breast cancer cells via activation of extracellular signal-regulated kinase through the $\mathrm{G}$ proteincoupled receptor 30. Mol Pharmacol 2008; 74: 1533-1543. http://dx.doi.org/10.1124/mol.108.046854

[45] HARWELL DME, RICHER JK, SINGH M, SPOELSTRA N, FINLAYSON C et al. Estrogen regulated gene expression in response to neoadjuvant endocrine therapy of breast cancers: tamoxifen agonist effects dominate in the presence of an aromatase inhibitor. Breast Cancer Res Treat 2008; 112: 489-501. http://dx.doi.org/10.1007/s10549-008-9923-6

[46] WAGNER AD, THOMSSEN C, HAERTING J, UNVERZAGT $S$ Vascular-endothelial-growth-factor (VEGF) targeting therapies for endocrine refractory or resistant metastatic breast cancer. Cochrane Database Syst Rev 2012; 7: CD008941.

[47] CHOD J, ZAVADOVA E, HALASKA MJ, STRNAD P, FUCIKOVA T et al. Preoperative transforming growth factorbeta 1 (TGF beta 1) plasma levels in operable breast cancer patients. European Journal of Gynecological Oncology 2008; 29: 613-616. 